International Journal of Behavioral Research \& Psychology (IJBRP)

ISSN 2332-3000

\title{
Mind fulness and Music: A Promising Subject of an Unmapped Field
}

Research Article

Oscar Lecuona de la Cruz ${ }^{1}$, Raquel Rodríguez-Carvajal ${ }^{*}$

${ }^{1}$ Clinical Psychology Student, Faculty of Psychology, Autonoma University of Madrid, Madrid, Spain.

${ }^{2}$ Associate Professor, Faculty of Psychology, Department of Biological and Health Psychology, Division of Personality, Evaluation and

Treatment, Autonoma University of Madrid, Madrid, Spain

\begin{abstract}
Mindfulness is defined as sustained, non-judgmental attention towards the world and the self. Several recent studies are bringing this concept into cutting-edge research and creating important contributions for the clinical context. In spite of this fact, there is a promising but unmapped field of research around specific contributions of mindfulness to music, and more specifically, for musicians. This article reviews this topic in order to show the state of the art of mindfulness related to music and help further advancement. A total of 27 publications were reviewed. The main conclusion is that despite its youth, this field is yielding some promising results in several dimensions: (1) effectiveness in mindfulness-based intervention programs for professional and hobby performers, (2) attention and concentration boost because of mindfulness induction in music audience, (3) effective induction of mindfulness states by music, and (4) promising contributions of mindfulness and music therapies. Finally, some guidelines and future lines are suggested for expanding and improving results, models, and methods.
\end{abstract}

Keywords: Mindfulness; Meditation; Music; Performers; Audience; Musicians; Music Performance Anxiety.

\section{*Corresponding Author:}

Raquel Rodríguez-Carvajal,

Faculty of Psychology, Department of Biological and Health Psychology, Division of Personality, Evaluation and Treatment, Autonomous University of Madrid, Madrid, 28049, Spain.

Tel: +3491497 5122; Fax: +34914976409

E-mail: raquel.rodriguez@uam.es

Received: March 22, 2014

Accepted: April 11, 2014

Published: April 12, 2014

Citation: Raquel Rodríguez-Carvajal, Oscar Lecuona de la Cruz (2014) Mindfulness and Music: A Promising Subject of an Unmapped Field . Int J Behav Res Psychol. 2(3), 27-35. doi: http://dx.doi.org/10.19070/23323000-140006

Copyright: Raquel Rodríguez-Carvajal ${ }^{\circ} 2014$ This is an open-access article distributed under the terms of the Creative Commons Attribution License, which permits unrestricted use, distribution and reproduction in any medium, provided the original author and source are credited.

\section{Introduction}

Many musicians could describe performing as a touching, intense, and high concentrated experience. The performer's mind is getting through the music piece with an intense attention and concentration to every aspect to assure the best outcome. Also, the performer's mind is aware of the audience remaining silent and listening to the performance, activating the stress-response for a social stimulus. As many musicians report, this intense situation of perceived scrutiny may lead to a stressful response and threating experience [1]. In this situation, many musicians develop the so-called stage fright, or music performance anxiety (MPA)[2], a disrupting group of symptoms that could stop or difficult a performer's career. On the opposite side, many performers describe this experience as full, not painful, joyful and emotional, hence meeting flow experiences [3]. At the same time, the audience is putting all their senses into the performance, listening and feeling what the performer has to express with intense attention. This experience of intense present-orientation and focus is compared in scientific literature with "peak experiences", or flow [4].

Could this intense, emotional, demanding and present-centered peak experiences have something in common with mindfulness? This review focuses on these topics. For that purpose, several sources and scientific databases were consulted. The first conclusion was that although promising contributions, there was not a general overview or "map" to get oriented in this topic literature. Hence, more awareness of contributions and systematization of knowledge seem necessary. This paper tries to help in satisfying this necessity.

\section{Mindfulness}

Mindfulness is usually defined as "paying attention in a particular way: On purpose, in the present moment, and non-judgmentally" [5]. Based on this definition, empirical research on mindfulness began importing Eastern Buddhist practices, such as meditation, into Western culture. On this process some modifications and conversions were performed, mainly depriving them of religious or specific moral backgrounds [6]. This western translation has encountered its main development within Health Sciences, especially Psychology and Behavioral Medicine, originating several contributions at diverse levels.

Several intervention programs have been designed and tested. Perhaps, one of the most widespread is the Mindfulness Based Stress Reduction (MBSR), developed by Jon Kabat-Zinn and colleagues. It focuses on using mindfulness to damper stress, reducing suffering and increasing psychological well-being. Numerous programs were implemented in several populations like pupils with chronic pain, cancer, arthritis, or fibromyalgia [1,3]. Another example of intervention program is the Mindfulness Based Cognitive Therapy (MBCT). It focuses on using both mindfulness 
and cognitive behavioral therapy to treat different syndromes like depression [8], generalized anxiety disorder [9], generalized social anxiety disorder [10], social anxiety disorder [11-13], bipolar disorder [14], panic disorder [15], or hypochondriasis [16]. Evidence has been found even in heterogeneous psychiatric samples [17, 18]. Mindfulness has also been associated with greater physical health, in terms of less somatization, and an increased awareness and attention to somatic experience (e.g., increased skin clearing in psoriasis disease), as well as decreased ambulatory measures, less blood overpressure, and a better immune system response to influenza or other hazards [19]. In spite of being vanguard research, it can be assumed that mindfulness is an effective tool for many clinical populations, either within mental health or medical contexts (e.g., tinnitus [20]).

In other contexts, mindfulness practice has been found to enhance spirituality, and as a couple, both factors (mindfulness and spirituality) have influence in decreasing reported psychological and medical symptoms [21]. Also, mindfulness seems to contribute to self-care to therapists in training [22].

\section{Mindfulness abroad}

Mindfulness has also been associated with psychological health and well-being in general population. Specifically, research relates dispositional mindfulness (as a general disposition in the individual) with increases in psychological well-being [23], as well as decreased neuroticism and psychopathological indexes [24]. More specifically, it seems that dispositional mindfulness is positively associated with self-esteem, optimism, positive emotional states, life satisfaction and eudemonic well-being, as well as it is moderately associated with emotional intelligence. In contrast, it is inversely associated with social anxiety, rumination, anxiety, depression, negative emotional states, and neuroticism. In a more neurological context, several contributions have been done to account the effects of mindfulness in the brain and the central nervous system. Some results indicate functional modifications in several brain networks, but also, and surprisingly, structural modifications of brain areas because of the effect of mindfulness [27-29].

It also seems that dispositional mindfulness is an effective predictor of diary self-regulation and well-being, both in clinical and general context. This is supported by self-report and also by lab evidence, particularly in extent to the influence of mindfulness and self-concordance between implicit and explicit processes [21]. Also, it seems to be enhanced by practice since significant differences were found between practitioners and non-practitioners [21]. Expanding this idea, it was specifically found that there was less dissociation, alexithymia, rumination, general psychological distress and mood disturbance $[14,15]$.

Beyond those basic frameworks, some contributions were made taking into account mindfulness and other aspects of well-being. In a more social context, dispositional mindfulness has been associated with marital relationship health and, in a complementary way, situational mindfulness was related with better communication during a discussion [31]. Another example is in mindfulness and intrinsic value orientation, were significant associates to both subjective well-being (e.g. life satisfaction) and ecological wellbeing (e.g. respect to nature), which leads to a conclusion towards compatibility of both ways of personal and collective well-being [32]. From an economical and financial perspective, mindfulness seems to play a role into diminishing financial desire discrepancy (distance between real and desired financial state) and increas- ing, therefore, subjective well-being [33]. In other words, "having enough with what one has". Also, mindfulness seems to enhance moral decision making in a cheating context [34]

In summary, mindfulness appears to be an expanding topic of research with non-frequent but strong contributions of its therapeutic effectiveness for many clinical populations, and also of its effects in enhancing psychological health and self-regulation.

\section{Music Performance Anxiety}

Although there is a lot of evidence on mindfulness and an increase of positive variables and diminishment of negative ones, we question: Could musicians be a population sensitive for being benefited from mindfulness? Do musicians suffer from significant psychology-related problems susceptible to be solved through a mindfulness intervention? Would it be even possible to increase musicians' performance with a mindfulness training? It seems that these questions could have an affirmative answer.

The music profession appears to be a competitive, demanding and high-task occupational field, with great personal demands on performers $[42,43]$. The career begins with an extended, time consuming training and continues with a demanding context of social evaluation. This process might induce performance anxiety, and utterly stage fright [1]. As Kenny and Steptoe defend [1, 35], performance anxiety is a common phenomenon in several activities such as test-taking, public speaking, sports, and performing arts. Thus, it can occur in a continuum from normal healthy anxiety and stress, to the problematic, debilitating and disrupting symptoms of stage fright. This phenomenon seems to be the most frequent non-musculoskeletal medical problem among musicians [1].

Stage fright is defined as a subtype of social phobia [37], and therefore considered a clinical disorder in the area of mental health. This concept has a more broad basic process, namely "music performance anxiety" (MPA), and defined by Steptoe [35]. It appears to present a deviation towards women [1], with the largest proportion of prevalence of music performance anxiety (MPA). Also it seems to be an association with trait anxiety and MPA, while not with occupational stress [2]. Cognitive models of social phobia make a valid account for the cognitive processes of MPA, mainly focused on social evaluation of the audience: audience view of the performance, audience standards, discrepancy between audience view and standards, perceived likelihood of negative evaluation, and importance of consequences of that negative evaluation. Those types of cognitive schemes (core beliefs and assumptions), associated with diathesis factors (critical past aversive events, low self-esteem or self-efficacy, etc.) may induce to maladaptive cognitions and survival rules (e.g. "I can't make mistakes") producing, therefore, MPA [38]. Treatments for MPA and stage fright were imported from, mainly, cognitive-behavioral therapy (CBT) and combined treatments with CBT and pharmacologic therapy. There has been some considerable contributions with modest efficacy, but lack of strong methodologies and larger scales of study bring need of rigorous, evidence-based, scientific contributions to asses MPA with the best efficacy [41].

Up to the knowledge of the authors, there are no systematic reviews analyzing if mindfulness and music performing (e.g. MPA) or listening are related or can interact. Neither there is any study reporting a methodologically strong efficacy of a mindfulnessbased intervention program with MPA. To this point, some clues 
we follow could justify this possible interactions between mindfulness and music: (1) MBSR seems to be effective treating social anxiety disorder [10-13], showing a positive and good influence compared with cognitive-behavioral therapy, the actual treatment of choice. (2) Also, trait mindfulness seems to modulate neuroendocrine response to social stressors [40], concretely with cortisol. Consequently, it can be inferred that mindfulness could be related to music performance anxiety, due to its relation to the broad branch of social anxiety. (3) In addition, there are peer-reviewed studies reporting efficacy of meditation-based intervention programs (in this case, Zen meditation) with specifically MPA [4849]. (4) Regarding music listening, mindfulness seems to interact with music audience [43]. (5) In a music therapy context, mindfulness seems to play an active role [44]. From all of this, this review article focuses on the broad topic of the possible interactions of mindfulness and music as a stimulus (e.g. to the audience) or as a response (e.g. to musicians).

\section{Materials and Methods}

Computer and manual searches were conducted to find research papers regarding empirical and theoretical findings of mindfulness specifically applied to the field of music, either of three possibilities: (1) as a stimulus (e.g. effects on the audience), (2) as a response (e.g. effects on performers or in composers), or (3) as a complement to mindfulness (e.g. mindful listening). The search was conducted for publications from the past ten years (20032013). The combinations of keywords were introduced into three databases: PsychINFO, PubMed, and Google Scholar. The keywords were mindfulness, mindfulness meditation, music, musical, musicians, music performers, music performing, music performance anxiety, music listening, audience, and flow. Afterwards, peer-reviewed articles, theses, dissertations, and books were chosen as a primary selection. To find older relevant publications, a retrospective secondary search was conducted based on references of the retrieved high impact scientific journals, selecting the most cited ones and related publications within those primary

Figure 1: Flowchart of inclusion/exclusion procedures for reviewed articles.

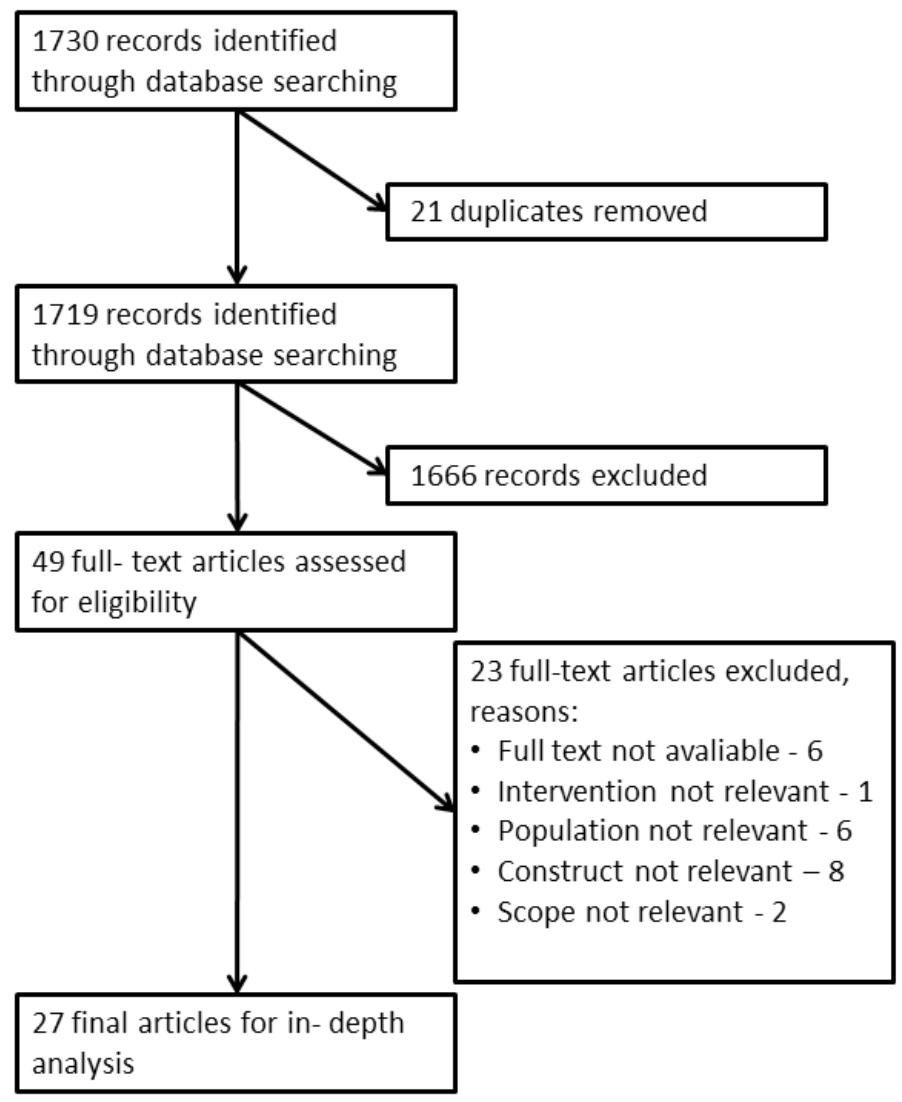

Table 1: Types and number of publications found

\begin{tabular}{|l|l|}
\hline Type of publication & Number of publications \\
\hline Peer-reviewed articles & 15 \\
\hline Book Sections & 1 \\
\hline Theses and Dissertations & 8 \\
\hline Conference Proceedings & 3 \\
\hline TOTAL & 27 publications \\
\hline
\end{tabular}


selected. A flowchart of the inclusion procedure is displayed in Figure 1.

\section{Results And Discussions}

The results of the review were organized as four main parts in the following lines. First of all, in Section 3.1, we focus on music as a response and on to what extent mindfulness and meditation influence that response in music performance. In this section the main interaction investigated is the benefits of meditation in MPA, while some attention is devoted to musical performance quality. Afterwards, in Section 3.2, we describe the effects of music as a stimulus and its possible interactions with mindfulness meditation. In this section, some interactions are reported, specifically the influence of mindfulness within the audience, and the influence of mindfulness and music to cope with other issues (e.g. depression). Then, in Section 3.3, we focus on music as a therapy and on to what extent mindfulness can influence that therapeutic process. Lastly, Section 3.4, provides a selection of webpages about mindfulness and music in order to show the popular impact of mindfulness in music.

As an overview of the methodology used in the studies found and hereinafter reviewed, Table 2 shows the main methodological designs. To explore a deeper methodological assessment of quantitative studies, we have separated those studies into two tables: Table 3 reports intervention studies with their methodological considerations, and Table 4 reports experimental and cross-sec-

\section{Table 2: Main methodological scope}

\begin{tabular}{|l|c|c|c|}
\hline Designs & Quantitative & Qualitative & Theoretical \\
\hline Studies & & & \\
\hline [43] Diaz (2010, 2011) & $\mathrm{X}$ & & \\
\hline [45] Bakker (2005) & $\mathrm{X}$ & & \\
\hline [46] Langer et al (2009) & $\mathrm{X}$ & $\mathrm{X}$ & \\
\hline [47] Farnsworth-Grodd (2012) & $\mathrm{X}$ & & \\
\hline [42] Cope et al (2009) & $\mathrm{X}$ & & \\
\hline [48] Chang et al (2003) & $\mathrm{X}$ & & \\
\hline [49] Khalsa et al (2013) & $\mathrm{X}$ & & \\
\hline [41] Lin et al (2008) & $\mathrm{X}$ & & \\
\hline [50] Monti et al (2006) & $\mathrm{X}$ & & \\
\hline [51] Stern et al (2012) & $\mathrm{X}$ & & \\
\hline [52] Robarts (2009) & $\mathrm{X}$ & & \\
\hline [53] Wolfe (2009) & $\mathrm{X}$ & & \\
\hline [54] Steyn (2013) & $\mathrm{X}$ & & \\
\hline [55-58] Vidyarthi et al (2012a, 2012b, 2013, in press) & & $\mathrm{X}$ & \\
\hline [59] Coholic (2011) & & $\mathrm{X}$ & \\
\hline [60] Fidelibus (2004) & & $\mathrm{X}$ & \\
\hline [61] Brown (2011) & & $\mathrm{X}$ & \\
\hline [44] Eckhardt, Dinsmore (2012) & & & $\mathrm{X}$ \\
\hline [62] De Felice (2004) & & & \\
\hline [63] Oyan (2006) & & & \\
\hline [64]Xu (2010) & & & \\
\hline
\end{tabular}

Table 3: Intervention studies with their methodological designs

\begin{tabular}{|l|l|l|l|l|l|}
\hline Designs & Control Group & Randomized & Follow-Up & Blind / Double blind & Others (case studies) \\
\hline Studies & & & & & \\
\hline $\begin{array}{l}{[42] \text { Cope et al }} \\
(2009)\end{array}$ & $\mathrm{X}$ & $\mathrm{X}$ & $\mathrm{X}$ & & \\
\hline $\begin{array}{l}{[48] \text { Chang et al }} \\
(2003)\end{array}$ & $\mathrm{X}$ & & & & \\
\hline $\begin{array}{l}{[49] \text { Khalsa et al }} \\
(2013)\end{array}$ & $\mathrm{X}$ & & & & \\
\hline$[41]$ Lin et al (2008) & $\mathrm{X}$ & $\mathrm{X}$ & & & \\
\hline$[50]$ Monti (2006) & $\mathrm{X}$ & $\mathrm{X}$ & & & \\
\hline$[51]$ Stern $(2012)$ & & & $\mathrm{X}$ & & \\
\hline$[52]$ Robarts (2009) & & & & & $\mathrm{X}$ \\
\hline$[54]$ Steyn $(2013)$ & $\mathrm{X}$ & & $\mathrm{X}$ & & \\
\hline
\end{tabular}


Table 4: Experimental and cross-sectional studies with their methodological designs

\begin{tabular}{|l|l|l|}
\hline Designs & $\begin{array}{l}\text { Experimental } \\
\text { (lab-based) }\end{array}$ & $\begin{array}{l}\text { Cross-Sectional } \\
\text { (self-report-based) }\end{array}$ \\
\hline Studies & & \\
\hline [43] Diaz (2010, 2011) & $\mathrm{X}$ & \\
\hline$[53]$ Wolfe (2009) & $\mathrm{X}$ & \\
\hline$[45]$ Bakker (2005) & & $\mathrm{X}$ \\
\hline [46] Langer (2009) & & $\mathrm{X}$ \\
\hline [47] Farnsworth-Grodd & & $\mathrm{X}$ \\
\hline (2012) & & $\mathrm{X}$ \\
\hline [54] Steyn (2013) & & \\
\hline
\end{tabular}

tional studies and their methodological considerations.

As Table 2 shows, the majority of the studies reviewed adopt a quantitative methodological scope, with few mainly qualitative scopes or theoretical essays. The only exception is [46], with a mixture of quantitative-qualitative scopes.

As Table 3 shows, the majority of intervention studies have control group, although only three of them have a randomized group assignment and only two have follow-up measures. Only one study [42] accomplishes those three methodological conditions. None of the studies reviewed adopts blind or double blind designs. Finally, Table 4 shows only one experimental study and three cross-sectional studies. Although the cross-sectional studies have strong methodological analyses (modelling, regression modelling, structural equation modelling, etc.) this evidence suggest lack of empirical, lab-based studies, thus empirical and theoretical need for well-driven studies.

\section{Mindfulness and Music Performing}

The effects of meditation on MPA were first reported in 2003, showing a significant decreased of trait anxiety in music performers[48] as the mainly outcome, but no effects were found in music performance concentration or state anxiety. From this, point, a first wave of studies reported promising results to meditation and MPA. This first wave of studies had an exploratory nature of the possible positive effects of mindfulness in MPA. Although one had an empirical scope [48], the most prevalent body of work was theoretical.

In 2008, through Zen meditation, evidence suggested consistency with the damping effect of meditation and MPA at a dispositional level, but not within a situational level. In this study, Music Performance Quality (MPQ) was negatively associated with MPA in the control group, but was positively associated in the experimental group. In addition, these associations were stronger when scoring post-performance than in general punctuations [41,64]. Authors concluded, first of all, that meditation could be useful to damper general MPA and trait anxiety. Secondly, Zen meditation might work as a resource to change a possible hindrance like MPA to a challenge in order to use MPA as a means to enrich their interpretation. That is to say, MPA was not inhibited in interpretations but maintained, and meditation skills empowered performers to foster their interpretation and increase their quality. Subsequently, we could hypothesize that mindfulness training could increase MPQ. One study might support this assumption [46], reporting the same effect and assessed by performers and audience. In this study the authors claimed that having musicians mindfully inserted in a performance leads them to insert subtle, spontaneous modifications and enjoy the performance. Consequently, this effect was reflected by the audience, making them enjoying the performing even more. These two affirmations were evaluated with a self-report methodology: (1) Performers were instructed to perform the same piece like "the finest performance of this piece you can remember" (control/fixed goal condition) and like "the finest way you can, offering subtle new nuances to your performance" (experimental condition). To ensure a mindfulness induction, a qualitative questionnaire for state mindfulness was developed and applied with positive results. (2) Moreover, members of a chorus were assembled and listened to both recordings. Then, they were asked if they noted a difference and if they had a preference to one of the recordings. Effects were consistent in replication, and controlled for a practice bias (performers) and for an order bias (audience).

This new understanding led to other studies to explore this regulatory effect, suggesting general emotion regulation through yoga intervention [49, 51] and mindfulness meditation [54]. In this last study, exploring the regulating function of mindfulness in MPA, Farnsworth-Grodd developed a theoretical model, stating mediating mechanisms in mindfulness and MPA. As it could be hypothesized, acting with awareness was the greatest predictor of lower MPA. Also, this variable, essential in mindfulness, received other influences in dispositional (e.g. studying or practicing music) and situational (e.g. concerts and shows) contexts. Such predictors were: higher hope, lower avoidance, and increased goal-orientated strategy in a dispositional level (practicing music); and positive focus, self-kindness, and self-acceptance in a situational level (during a performance). It could be possible to link this self-regulatory and positive effect with some exploratory evidence: from (1) an increased psychological well-being and mental performance in music students after a mindfulness intervention [54], to (2) an increased flow response linked to mindfulness states while performing [61].

In another trend, some research was performed with yoga interventions analyzing its effects in Performance-Related Musculoskeletal Disorders (PRMD), besides MPA. While one study reports no changes in PRMDs with yoga interventions [42], another study reveals inconsistent results [49]. The authors of the last study report a significant effect in one sample compared to the control group while non-significant in another. Some possible reasons for this inconsistency were explained by the authors: (1) Low baseline scores in PRMDs, revealing a healthy musicians sample and a possible floor effect, and (2) not long enough duration of the program to produce significant stable effects [49]. A general conclusion is an uncertain issue that needs to be explored 
and explained, hence a deeper study is necessary.

\section{Mindfulness and Music Listening}

Attending to music as a stimulus, only a few contributions have been found. The most directly related contribution is a research project by Frank Diaz [4, 43], analyzing effects of mindfulness and flow in the audience. Using Continuous Response Digital Format (CRDI) and self-reports, music pieces were exposed to a selected sample audience. Participants were randomly assigned into three groups: (1) mindfulness induction and aesthetic response, (2) mindfulness induction and flow response, (3) aesthetic response only, and (4) flow response only. The procedure to induce mindfulness was a 15 minute recorded guided induction, centered in a body scan meditation procedure. Results of this work indicate no significant differences in attention, which were based on summative accounts. However, self-reports and verbal responses revealed differences between groups, highlighting benefits of mindfulness induction in the attention task leading to a decreased mental distraction, increased awareness of music characteristics, and an enhanced focus. In addition, it seems that magnitude response was also behaving like attention or attentiveness. Summative accounts report no significant differences in participants' level of magnitude, but real time data analysis brings up differences regarding mindfulness. It seems that mindfulness has a differential effect on flow and aesthetic responses. As regards to flow, magnitude tends to have an overall decrease, whereas for aesthetic response, an overall increase. This differential influence could be interpreted as mindfulness having an empowering role for the participants' goal: if they want to concentrate and not be distracted, mindfulness helps decreasing affective response; and if they want to enjoy and get immersed in the most powerful way, mindfulness can boost their peak affective experiences, and therefore, increase response magnitude (intensity). And both effects might be explained by the increase of awareness, the difference lays on the goal of the subject.

In a different way, a research project proposed music listening (or even sound listening) as a feedback source to the subject in order to cultivate mindfulness, namely "The Sonic Cradle Project". It is based on a device that is defined as "a chamber of complete darkness where users shape a peaceful soundscape using only their respiration" [55]. The subject lies in a suspended hammock hanging from the ceiling of the chamber and surrounded by darkness (to avoid visual or interoceptive distractions). Then, the real-time measurements of the subject's breathing modulates the musical stimulus (type of instrument, pitch, rhythm, etc.), thus closing the feedback loop [56]. Through this biofeedback device, the authors pretend to foster meditation and mindfulness skills to the users of the device and to divulgate and facilitate mindfulness mindsets to non-practitioners [57]. Evidence suggests that its effects are really similar to mindfulness meditation $[57,58]$ reporting loss of intention, relaxation, positive emotional responses, reduced thinking ("emptiness") and self-awareness. Meditators compared the experience highly with ordinary meditations [58].

In this context, a theoretical framework is established based on the salutary effects of music listening, but also proposing attentional and metacognitive mechanisms (and thus, mindfulness) to cause these positive effects. Moreover, experimental evidence shows an attentional improvement (one key factor of mindfulness) because of musical content in a vigilance task with auditory distractors in kindergarten children [53].
Thus, it seems that music listening can induce mindfulness states, with consequential benefits, e.g. improved attention or improved peak response intensity.

\section{Mindfulness and Music Therapy}

Some studies explored the conjunction of mindfulness and music as an intervention for applied contexts (e.g. clinical or educational). Some explorations have been carried out with interesting conclusions. For instance, Coholic [59] proposes Arts-Based Mindfulness-Based Practices for young children in need. This program pretends to train mindfulness skills with art practices, seeking clinical goals, such as emotion regulation, social and coping skills, self-esteem, resilience, and self-awareness. These findings seem to be similar in another studies [52]. The mindfulness effects on music therapists when performing clinical music therapy improvisation has also been studied, showing a qualitative prevalence of mindfulness states in the music therapists [65-67].

In another clinical context, Monti et al [50] proposed a Mindfulness-Based Art Therapy (MBAT) for women with cancer. This program, hybridized between the MBSR protocol and art therapies, focuses on training mindfulness skills using art practices. The MBAT has shown efficacy in reducing psychological distress and enhancing quality of life. One particularity of the MBAT could be its own name, because attending to its main curriculum the great majority of art-related exercises are of plastic art (e.g. painting) practices. Nevertheless, the final exercises are open to any form of art, including music, and the evidence exposed underpins promising results when in conjunction applying mindfulness and music for clinical or educational purposes.

In a parallel way as in music performing, music listening and mindfulness could be studied in conjunction for applied contexts. One study explored this possibility [44]. Using their appointed Mindful Music Listening (MML), the authors applied music listening practices combined with mindfulness training to patients with depression. Results show an enhanced emotion regulation, greater self-awareness and a strengthened therapeutic relationship. Thus, listening to music with a mindful disposition leads to positive outcomes (e.g. enhanced emotion regulation or selfreference).

In conclusion, it seems that mindfulness can contribute to musical therapy programs to enhance their efficacy. And, to achieve this goal, music can be employed by both performing or listening dimensions.

\section{Conclusions and guideslines for future research}

The present review encourages research in mindfulness and music towards a better understanding of its object of study. With a better mapping of the state of the art, and a condensed view of the latest results, researchers can get their job done quicker. This seems to be a little explored field (according to results in Table 1), but shows promising results and thus seemingly offering potential. In general it seems that mindfulness can be characterized by an important interaction with the art of music in many contexts, thus deserving research and exploratory applications: (1) mindfulness could improve MPQ by mediating the positive relationship between MPA and MPQ, thus turning MPA into performancefacilitating, apart from enhancing psychological well-being in 
Figure 2: Proposed map of interactions between music and mindfulness.

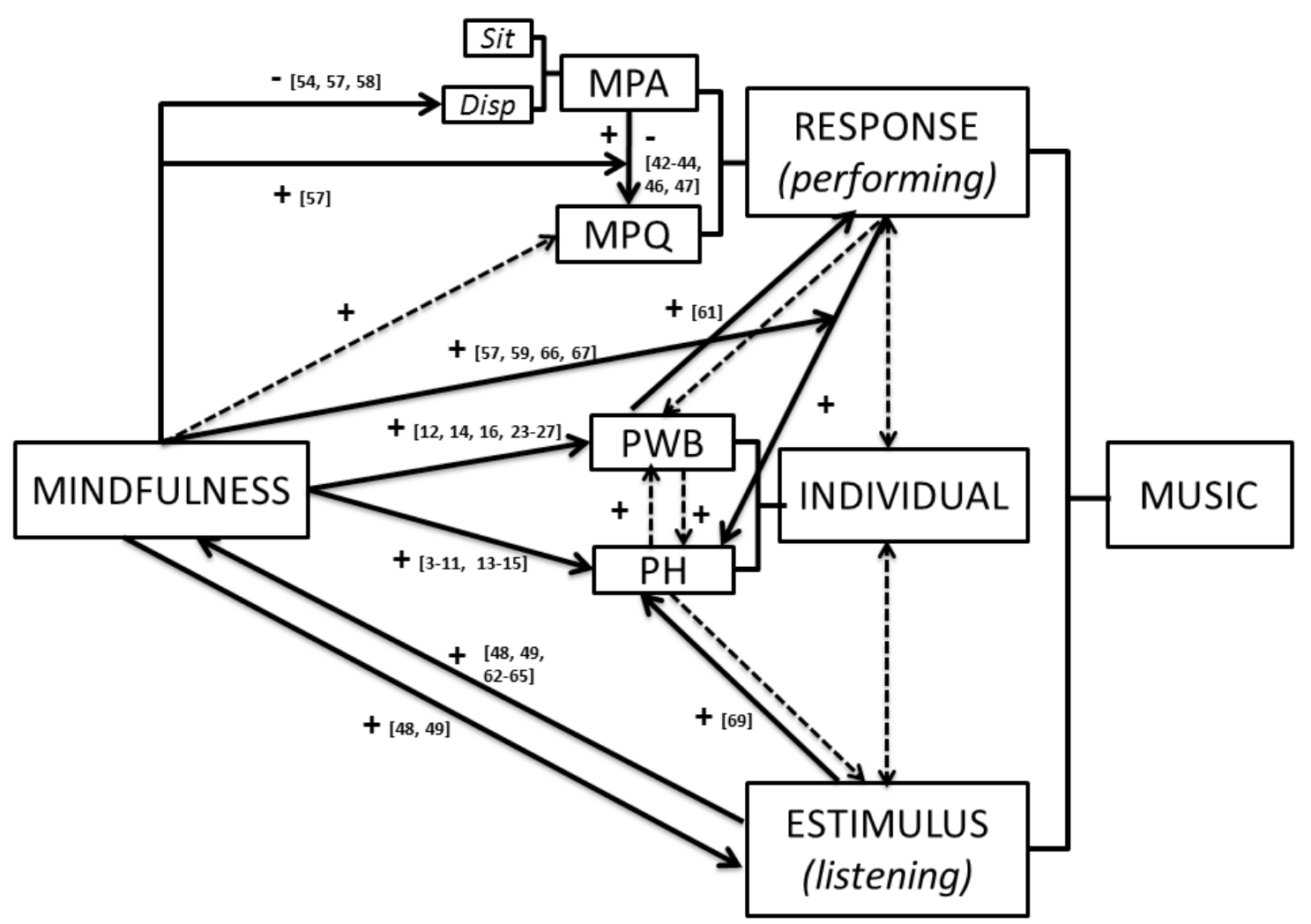

\author{
MPA = Music Perfomance Anxiety \\ Sit = Situational \\ Disp $=$ Dispositional \\ $\mathrm{MPQ}=$ Music Performance Quality \\ PWB = Psychological Well-Being \\ $\mathrm{PH}=$ Psychological Health.
}

musicians; (2) mindfulness could enhance music listening, raising the intensity of peak responses; (3) music listening could contribute to mindfulness induction (4) music performing could be for therapeutic use in relation with mindfulness to foster clinical treatments.

Based on these interactions, a possible map of the existing contributions is displayed in Fig. 2, showing each possible interaction between mindfulness and music. Bold connections are referred to actually researched interactions, whereas dotted connections are allocated for general coherence of the model.

As it can be seen in the present review, a substantial part of the domains of music has been explored, but with parts still in an unexplored state and with much progress awaiting and research to be done in the already explored fields. More theoretical development seems necessary, as well as further examination on conceptual definitions and hypothesis fabrication. Also, as it was stated in the initial results section, although the majority of studies reviewed have quantitative methodologies, there seems to be still few empirical studies in the field. Furthermore, there is a lesser amount with experimental designs, remaining quantitative studies just mainly cross-sectional or intervention designs. Thus, the methodological strength of these findings remains somehow unstable as a consequence of the youth of the field, in opinion of the authors.
Future research in this field could not only well theoretical founded studies are needed but also to improve the accuracy of designs, increasing longitudinal, diary and lab-based experimental studies. Also, some dimensions seemsstill unexplored. One example is the exploration of mindfulness in what relates to music creation. For example, composing or improvising could be also influenced by related processes, like flow or creativity, both related to mindfulness. Furthermore, music could be studied as a stimulus inducer to mindfulness, which has been only scouted initially. Research also could explore possible roots of western culture within mindfulness and music from an anthropological or musicological approach, hence enhancing theoretical frameworks.

\section{References}

[1] Kenny DT and Osborne MS (2006) Music performance anxiety: New insights from young musicians. Advances in Cognitive Psychology 2 (2): 103-112, Jan.

[2] Kenny DT, Davis P, and Oates J (2004) Music performance anxiety and occupational stress amongst opera chorus artists and their relationship with state and trait anxiety and perfectionism., Journal of Anxiety Disorders, 18 (6): 757-777, Jan.

[3] Wrigley WJ and Emmerson SB (2011) The experience of the flow state in live music performance. Psychology of Music 41 (3): 292-305, May. DOI $10.1177 / 0305735611425903$.

[4] Díaz FM (2011) Mindfulness, attention , and flow during music listening : An empirical investigation, Psychology of Music, 41 (1): 42-58.

[5] Kabat-zinn J (1990) Full catastrophe living: Using the wisdom of your body and mind to face stress, pain, and illness. Bantam Dell, New York, USA.

[6] Snyder CR and Lopez SJ (Eds.) (2002) Oxford Handbook of Positive Psy- 
chology. Oxford university Press, New York, USA, p. 829

[7] Veehof MM, Ten Klooster PM, Taal E, Westerhof GJ, and Bohlmeijer ET (2011) Psychometric properties of the Dutch Five Facet Mindfulness Questionnaire (FFMQ) in patients with fibromyalgia. Clinical Rheumatology 30(8): 1045-1054 Aug

[8] Kuyken W, Byford S, Taylor RS, Watkins E, Holden E et al (2008) Mindfulness-based cognitive therapy to prevent relapse in recurrent depression.. Journal of Consulting. and Clinical Psychology 76 (6): 966-978 Dec.

[9] Evans S, Ferrando S, FindlerM, Stowell C, Smart C et al (2008) Mindfulness-based cognitive therapy for generalized anxiety disorder. Journal of Anxiety Disorders 22 (4): 716-721 May.

[10] Koszycki D, Benger M, Shlik J, and Bradwejn J (2007) Randomized trial of a meditation-based stress reduction program and cognitive behavior therapy in generalized social anxiety disorder. Behavior Research and Therapy 45 (10): 2518-2526 Oct.

[11] Goldin PR, Ramel W, and Gross J (2009) Mindfulness Meditation Training and Self-Referential Processing in Social Anxiety Disorder: Behavioral and Neural Effects. Journal of Cognitive Psychotherapy 23: 242-257.

[12] Goldin PR and Gross JJ (2010) Effects of mindfulness-based stress reduction (MBSR) on emotion regulation in social anxiety disorder. Emotion 10 (1): 83-91, Feb.

[13] Kocovski NL, Fleming JE and Rector NA (2009) Mindfulness and Acceptance-Based Group Therapy for Social Anxiety Disorder: An Open Trial. Cognitive Behavioral Practice 16 (3): 276-289, Aug.

[14] Williams JMG, Alatiq Y, Crane C, Barnhofer T, Fennell MJV et al (2008) Mindfulness-based Cognitive Therapy (MBCT) in bipolar disorder: preliminary evaluation of immediate effects on between-episode functioning. Journal of Affective Disorders 107 (1-3): 275-279 Apr

[15] Kim B, Lee S-H, Kim YW, Choi TK, Yook K et al (2010) Effectiveness of a mindfulness-based cognitive therapy program as an adjunct to pharmacotherapy in patients with panic disorder. Journal of Anxiety Disorders 24 (6): 590-595 Aug.

[16] Lovas DA and Barsky AJ (2010) Mindfulness-based cognitive therapy for hypochondriasis, or severe health anxiety: a pilot study. Journal of Anxiety Disorders 24 (8): 931-935 Dec.

[17] Green SM and Bieling PJ (2012) Expanding the Scope of MindfulnessBased Cognitive Therapy: Evidence for Effectiveness in a Heterogeneous Psychiatric Sample. Cognitive and Behavioral Practice 19 (1): 174-180 Feb.

[18] Chiesa A and Serretti A (2011) Mindfulness based cognitive therapy for psychiatric disorders: a systematic review and meta-analysis. Psychiatry Research 187 (3): 441-453 May.

[19] Brown KW, Ryan RM, and Creswell JD (2007) Mindfulness: Theoretical Foundations and Evidence for its Salutary Effects. Psychological Inquiry 18 (4): 211-237 Oct.

[20] Philippot P, Nef F, Clauw L, de Romrée M, and Segal Z (2012) A randomized controlled trial of mindfulness-based cognitive therapy for treating tinnitus. Clinical Psychology and Psychotherapy 19 (5): 411-419 Sep.

[21] Carmody J, Reed G, Kristeller J, and Merriam P (2008) Mindfulness, spirituality, and health-related symptoms. Journal of Psychosomatic Research 64 (4): 393-403 Apr.

[22] Shapiro SL, Brown KW, and Biegel GM (2007) Teaching self-care to caregivers: Effects of mindfulness-based stress reduction on the mental health of therapists in training. Training and Education in Proffesional Psychology 1 (2): 105-115.

[23] Brown KW and Ryan RY (2003) The benefits of being present: Mindfulness and its role in psychological well-being. Journal of Personality and Social Psychology 84 (4): 822-848.

[24] Baer RA, Smith GT, Hopkins J, Krietemeyer J, and Toney L (2006) Using self-report assessment methods to explore facets of mindfulness. Assessment 13 (1): $27-45 \mathrm{Mar}$

[25] Kilpatrick LA, Suyenobu BY, Smith SR, Bueller JA, Goodman T et al (2011) Impact of Mindfulness-Based Stress Reduction training on intrinsic brain connectivity. Neuroimage 56 (1): 290-298 May.

[26] Davidson RJ (2003) Alterations in Brain and Immune Function Produced by Mindfulness Meditation. Psychosomatic Medicine 65 (4): 564-570 Jul.

[27] Brewer JA, Worhunsky PD, Gray JR, Tang Y-Y, Weber J et al (2011) Meditation experience is associated with differences in default mode network activity and connectivity. Proceedings of the National Academy of Sciences of the United States of America 108 (50): 20254-20259 Dec. 2011.

[28] Brefczynski-Lewis JA, Lutz A, Schaefer HS, Levinson DB, and Davidson RJ (2007) Neural correlates of attentional expertise in long-term meditation practitioners. Proceedings of the National Academy of Sciences of the United States of America 104 (27): 11483-11488 Jul.

[29] Farb NAS, Segal Z, Mayberg H, Bean J, McKeon D et al (2007) Attending to the present: mindfulness meditation reveals distinct neural modes of selfreference. Social, Cognivite and Affective Neuroscience 2 (4): 313-322 Dec.

[30] Shapiro SL, Oman D, Thoresen CE, Plante TG, and Flinders T (2008) Cultivating Mindfulness : Effects on Well-Being. Journal of Clinical Psychology 64 (7): 840-863.

[31] Barnes S, Brown KW, Krusemark E, Campbell WK, and Rogge RD (2007)
The role of mindfulness in romantic relationship satisfaction and responses to relationship stress. Journal of Marital and Family Therapy 33 (4): 482500 Oct.

[32] Brown KW and Kasser T (2005) Are Psychological and Ecological Wellbeing Compatible? The Role of Values, Mindfulness, and Lifestyle. Social Indicators Research 74 (2): 349-368 Nov.

[33] Brown KW, Kasser T, Ryan RM, Alex Linley P, and Orzech K (2009) When what one has is enough: Mindfulness, financial desire discrepancy, and subjective well-being. Journal of Research in Personality 43 (5): 727-736 Oct.

[34] Shapiro SL, Jazaieri H, and Goldin PR (2012) Mindfulness-based stress reduction effects on moral reasoning and decision making. Journal of Positive Psychology 7 (6): 504-515 Nov.

[35] Steptoe A and Fidler H (1987) Stage fright in orchestral musicians: A study of cognitive and behavioural strategies in performance anxiety. British Journal of Psychology, 78: 241-249.

[36] Yoshie M, Kudo K, Murakoshi T, and Ohtsuki T (2009) Music performance anxiety in skilled pianists: effects of social-evaluative performance situation on subjective, autonomic, and electromyographic reactions. Experimantal Brain Research, 199, (2): 117-126, Nov.

[37] American Psychiatric Association (APA) (2013) DSM-5: Diagnostic and Statistic Manual of Mental Disorders. Washington DC: APA.

[38] Osborne MS and Franklin J (2002) Cognitive processes in music performance anxiety, Australian Journal of Psychology, 54 (2): 86-93, Aug.

[39] Kenny DT (2005) A Systematic Review of Treatments for Music Performance Anxiety. Anxiety, Stress and Coping 18 (3): 183-208, Sep.

40] Brown KW, Weinstein N, and Creswell JD (2012) Trait mindfulness modulates neuroendocrine and affective responses to social evaluative threat. Psychoneuroendocrinology 37 (12): 2037-2041, Dec.

[41] Lin P, Chang JC, Zemon V, and Midlarsky E (2008) Silent illumination: a study on Chan (Zen) meditation, anxiety, and musical performance quality. Psychology of Music 36 (2): 139-155.

[42] Cope S,. Wyshak ÆG, and. Sklar ÆE (2003) Yoga Ameliorates Performance Anxiety and Mood Disturbance in Young Professional Musicians. Applied Psychophysiological Biofeedback 34 (4): 279-289.

[43] Díaz FM (2010) A Preliminary Investigation into Effects of a brief Mindfluness induction on Perceptions of Attention, Aesthetic response, and Flow during music listening. Florida State university.

[44] Eckhardt KJ and Dinsmore JA (2012) Mindful music listening as a potential treatment for depression., Journal of Creativity in Mental Health, 7 (2): 176-186.

[45] Bakker AB (2005) Flow among music teachers and their students: The crossover of peak experiences, Journal of Vocational Behavior, 66 (1): 26-44, Feb.

[46] Langer E, Russel T, and Eisenkraft N (2009) Orchestral performance and the footprint of mindfulness. Psychology of Music 37 (2): 125-136, Apr.

[47] Farnsworth-Grodd VA (2012) Mindfulness and the Self-Regulation of $\mathrm{Mu}-$ sic performance Anxiety. University of Auckland.

[48] Chang JC, Midlarsky E, and Lin P (2003) The effects of meditation on music performance anxiety, Medical Problems Performing Artists, 18(3): 126-130.

[49] Khalsa SBS, Butzer B, Shorter SM, Reinhardt KM, and Cope S (2013) Yoga reduces performance anxiety in adolescent musicians., Alternative Therapies in Health and Medicine 19 (2): 34-45.

[50] Monti DA, Peterson C, Kunkel EJS, Hauck WW, Pequignot E et al (2006) A randomized, controlled trial of mindfulness-based art therapy (MBAT) for women with cancer., Psychooncology 15 (5): 363-373.

[51] Stern JRS, Khalsa SBS, and Hofmann SG (2012) A yoga intervention for music performance anxiety in conservatory students. Medical Problems Performing Artists 27 (3): 123-8, Sep.

[52] Robarts J (2009) Supporting the development of mindfulness and meaning: Clinical pathways in music therapy with a sexually abused child.. In Communicative musicality: Exploring the basis of human companionship, Malloch S and Trevarthen C, Eds. Oxford University Press, New York: 377-400.

[53] Wolfe DE and Noguchi LK (2009) The use of music with young children to improve sustained attention during a vigilance task in the presence of auditory distractions. Journal of Music Therapy 46 (1): 69-82, Jan.

[54] Steyn MH, The impact of psychological skills and mindfulness training on the psychological well-being of undergraduate music students, University of Pretoria, 2013

[55] Vidyarthi J (2012) Sonic Cradle : Evoking Mindfulness through 'Immersive Interaction Design. Simon Fraiser University.

[56] Vidyarthi J, Riecke BE, and Gromala D (2012) Sonic Cradle : Designing for an Immersive Experience of Meditation by Connecting Respiration to Music. Proceedings in DIS 2012.

[57] Vidyarthi J and Riecke BE (2013) Mediated Meditation: Cultivating Mindfulness with Sonic Cradle. CHI 2013 Extended Abstracts.

[58] Vidyarthi J and Riecke BE (in press) Interactively Mediating Experiences of Mindfulness Meditation, International Journal of Human-Computer Studies, Feb. DOI 10.1016/j.ijhcs.2014.01.006

[59] Coholic DA (2011) Exploring the Feasibility and Benefits of Arts-Based 
Mindfulness-Based Practices with Young People in Need: Aiming to Improve Aspects of Self-Awareness and Resilience. Child \& Youth Care Forum, 40 (4): 303-317, Jan.

[60] Fidelibus JF (2004) Mindfulness and music therapy clinical improvisation: When the music flows. New York University.

[61] Brown J (2011) In the zone : An autoethnographic study exploring the links between flow and mindfulness for a piano accompanist. Studies in Learning, Evaluation, Innovation and Development, 8 (2): 83-95, 2011.

[62] De Felice M (2004) Mindfulness Meditation: A new tool for understanding and regulating musical performance anxiety: An affective neuroscientific perspective. Dissertations from from ProQuest, Paper 2178.

[63] Oyan S (2006) Mindfulness Meditation: Creative Musical Performance
Through Awareness. George Mason University.

[64] Xu H (2010) Application of Zen Techniques to overcome Performance Anxiety. Florida State University.

[65] Grant A, Langer E, Falk E, and Capodilupo C (2004) Mindful Creativity: Drawing to Draw Distinctions. Creativity Research Journal 16: 261-265.

[66] Wright JJ, Sadlo G, and Stew G (2006) Challenge-skills and mindfulness: An exploration of the conundrum of flow process. OTJR: Occupation, Participation and Health 26 (1): 25-32.

[67] Reid D (2011) Mindfulness and flow in occupational engagement: presence in doing. Canadian Journal of Occupational Therapy 78: 50-56. 